\title{
LA CUEVA DE MONTESINOS: CONDENSACIÓN ONIRICA DE DOS TEXTOS DISÍMILES
}

En su ensayo «Discours in the Novel», Mikhail Bakhtin señala que Don Quijote es un espacio narrativo donde concurren diversas voces o discursos que subvierten la autoridad de los géneros literarios tradicionales. Estas múltiples voces o «poliglosia” - para usar la terminología del ensayista ruso-, están en una relación dialógica: los personajes, el autor, e incluso los diversos géneros literarios, «conversan» entre sí, se interrogan, refutan o parodian. Análogamente, el estudio de Walter Reed sobre las diferencias entre la picaresca y la novela -específicamente Don Quijote-, resalta el hecho de que mientras la primera tiende a una exclusión de discursos, la segunda apunta más bien a una inclusión de estos. El ethos de la novela de Cervantes, dice Reed, «is ironically inclusive. Alternative versions of experience are conjured up and entertained, even as their claims to truth are put into question» (73).

Correctas como nos parecen las tesis de Bakhtin y Reed, conviene indicar, sin embargo, que el modo como estos diversos discursos se articulan en la novela de Cervantes varía según nos refiramos a la primera o a la segunda parte de la misma. En la primera parte (que llamaremos Q1 para diferenciarla de Q2), la relación entre los discursos de los personajes expresa, más que un diálogo efectivo, un desencuentro de voces de registros disímiles. Don Quijote, Cardenio o Grisóstomo atienden más a sus propios paradigmas caballerescos o amorosos que a las razones de los otros. Como bien ha sefialado René Cirard, la relación de don Quijote con el mundo no es directa sino triangular: su contacto con la realidad está mediatizado por Amadís, paradigma de las novelas de caballería. El hidalgo de la Mancha vive a través de Amadís, y si se considera el 
espejo de la andante caballería es porque, literalmente, su existencia es casi el mero reflejo de otro. Las lecturas de don Quijote suprimen la distancia entre la realidad del presente y la realidad del mito. Si Alonso Quijano era todavía un lector que guardaba una distancia con el texto leído, don Quijote es más bien el resultado de una lectura. El lector ideal mantiene en una u otra medida una relación dialéctica con el texto; la lectura es un intercambio del discurso propio y el ajeno. Cuando esta dialéctica se pierde, Quijano se vuelve Quijote: un personaje imaginario salido de un libro de caballería. El texto devora al lector y su capacidad de discriminación. Del mismo modo, el discurso de don Quijote rompe la dialéctica con el otro: no es tanto un diálogo como un monólogo.

Pero en el Q2 se produce un cambio importante: don Quijote ahora no sólo lee (o es leído) en los textos de caballería, sino también lee el texto de sus propias aventuras. Su paradigma se desdobla: es Amadís, y también él mismo como personaje del Q1. El hecho produce una transformación decisiva en su personalidad e imaginación. En el Q1, el hidalgo de la Mancha se sabía el espejo de la caballería andante y su ánimo se contagiaba de la temeridad y la firmeza de propósitos de Amadís. Su amor por Dulcinea, su idealismo enderezador de entuertos, repetían la vida de los héroes épicos que había leído. Se entiende que la quema de sus libros ordenada por el cura no le afectara: los textos impresos sólo son un espejo degradado de un universo mítico que los precede y supera. Como ha señalado Bakhtin en su ensayo "Epic and Novel», en la medida que el universo de la épica se sitúa en un pasado remoto y absoluto, adquiere una condición sagrada e invulnerable a la degradación natural del presente. Pero la leyenda del ingenioso hidalgo de la Mancha, impresa y en circulación por el mundo, está demasiado próxima a la experiencia diaria del héroe como para que no pueda reconocer y cotejar las incoherencias entre una y otra. A diferencia de la leyenda de Amadís, don Quijote puede verse, tocarse, y saber cómo no siempre coinciden su persona y su leyenda. Es más, contrariamente a lo que ocurnía en el Q1, en el Q2 no puede manipular la leyenda a su antojo; ahora más bien es manipulado por ésta, representa un papel en un tinglado que no maneja, como los títeres en el retablo de maese Pedro. Este desencuentro entre la leyenda y la realidad o entre el texto impreso y su lector, despierta en don Quijote la consciencia de una brecha entre ambas instancias: en esta segunda parte el héroe empieza a cuestionar el talento y la honestidad del inventor de su historia: «Ahora digo que no ha sido sabio el autor de mi historia, sino algún ignorante hablador, que a tiento y sin discurso se puso a escribirla, salga lo que saliere...» (478). 
La fisura que se produce entre leyenda y realidad no implica que don Quijote empiece a tomar una distancia crítica frente a los textos de caballería. Sólo señala la emergencia de otro texto, no ideal como el anterior, y donde él ocupa el lugar de un discutible o vulnerable Amadís. En su imaginación concurren dos textos de registros diferentes, como si el espejo de la andante caballería proyectara ahora un doble y contradictorio reflejo. En el episodio del $\times \mathrm{Ca}$ ballero de los Espejos», don Quijote levanta la visera del caballero vencido y no encuentra un rostro caballeresco sino uno demasiado familiar: el del bachiller Sansón Carrasco. La visión refleja su misma ambigua condición. El personaje del mito se confunde con otro contemporáneo: delante de sí tiene a un caballero que es y no es tal. Una imagen no excluye a la otra: se incluyen de modo paradójico.

La idea de una «consciencia emergente» en Don Quijote no deja de ser problemática. Hablar de un principio de cordura, de un despertar de Alonso Quijano, como un pequeño punto de claridad que progresivamente irá desplazando las sombras de la locura de don Quijote hasta una epifanía final, no creemos que sea el caso aquí. La tensión o la dialéctica que se produce en la imaginación del protagonista no es una entre cordura y locura o entre realidad y ficción sino entre textos y lecturas diversos de la realidad. Dialéctica entre lectores y lecturas que Ruth El Saffar y James Parr consideran un rasgo distintivo de la novela de Cervantes:

The Quijote is a book about readers and readings, as Ruth El Saffar has shown convincingly. It is a complex blend of illusionistic and antiillusionistic elements, which is to say that certain features serve to draw the reader into de story being told, whereas others serve as reminders that it is an artificial construct, at last once removed from reality (Parr. 69).

La idea de una dialéctica entre lecturas y lectores, y no entre ficción y realidad, se desprende de la epistemología implícita en la novela, cuya deuda con el neoplatonismo ha sido puesta de relieve por varios autores. En el conocido mito platónico de la caverna, el ser humano no tiene acceso directo a la realidad porque está dentro de una caverna por cuyas paredes desfilan sólo sombras de esta realidad. Para el neoplatonismo, la interpretación o lectura de lo real nunca puede ser xobjetiva», pues todo discurso participa de la naturaleza ilusoria del conocimiento. El carácter ilusorio de toda lectura es sugerido por Cervantes en el prólogo de la novela, cuando irónicamente iguala al «desocupado lector» de su obra con Alonso Quijano - otro desocupado lector - cuya razón será finalmente vencida por la ilusión de la lectura. En este orden de cosas, la cordura 
no significa la capacidad de liberarse de la ilusión implícita en cualquier acto de lectura o interpretación de la realidad sino la capacidad de contrarrestar o panodiar una ilusión o una lectura con otra.

La nueva consciencia de don Quijote en la segunda parte de la novela debe ser entendida, en mi opinión, no como el inicio de la cordura del héroe sino como el principio de una pugna entre dos paradigmas de lecturas o de lectores que se enfrentan en su imaginación: un don Quijote-lector-de-Amadís y un don Quijote-lector-desí-mismo. Este desdoblamiento (cuya lógica ha requerido este preámbulo) creo que es esencial para entender las contradicciones que se encuentran en el relato de la cueva de Montesinos, propósito de este trabajo.

Los ensayos sobre este conocido episodio son bastantes, aunque sus puntos de vista son muchas veces antagónicos. La crítica ha tomado, básicamente, dos direcciones opuestas: los que conciben este episodio como una pesadilla del héroe, y los que lo ven como una culminación positiva y necesaria en el trayecto de todo caballero andante que se precie de tal. El angumento de los primeros parece, a primera vista, el más convincente ${ }^{1}$ : el descenso a la cueva es, figurativamente, la mirada introspectiva de un héroe que ha perdido la confianza en su misión, y refleja su presentimiento de la decadencia de los ideales caballerescos. Esta tesis se funda en el lastimoso cuadro que ofrecen los héroes épicos en el escenario imaginado por don Quijote. Durandarte, muerto en vida y con un corazón «seco y amojamadon, es la pesadilla en la que don Quijote puede leer su propio destino; Belerma «en sus grandes ojeras y en su color quebradizax anticipa el destino de Dulcinea; y ésta aparece como aldeana, mendigando una suma ridícula de dinero. La sensación de fracaso se refuerza con las palabras premonitorias de Durandarte, que manifiestan sus dudas sobre el éxito de la misión de don Quijote de resucitar la olvidada orden de la caballeria: «Y cuando así no sea - respondió el lastimado Durandarte con voz desmayada y baja-, cuando así no sea joh primo!, digo, paciencia y barajar» (605).

No obstante, como ya dijimos, la crítica no es unánime respecto al carácter apocalíptico o pesadillesco de la experiencia de la cueva de Montesinos. Los argumentos que sostienen un punto de vista contranio al anterior parecen igualmente convincentes ${ }^{2}$. Dice Gethin Hughes que si bien el episodio de la cueva de Montesinos es una parodia de los ideales caballerescos, ésta forma parte del dis-

1 Algunos criticos que senalan este aspecto - la pesadilla- de la experiencia del héroe en la cueva de Montesinos son Walter Reed, Helena Pencas Ponseti, E. C. Riley y Peter Dunn.

2 Son de esta opinion Gethin Hughes y Juan Bautista Avalle-Arce. 
curso del autor y no del discurso del héroe, que ve la escena en términos de sus propias preocupaciones. Si la devaluación de los valores caballerescos hubiese sido sólo una proyección de la imaginación de don Quijote, cómo explicar entonces, se pregunta Hughes, su entusiasmo a la salida de la cueva: «Dios os lo perdone, amigos -le dice don Quijote a Sancho y al primo-; que me habéis quitado de la más sabrosa y agradable vida y vista que ningún humano ha visto ni pasado» (599). Con el mismo entusiasmo el hidalgo manchego replica a Sancho y al primo cuando éstos le piden que les cuente lo que ha visto "en su viaje al infierno": «¿Infierno le llamáis? Pues no le llaméis ansí, porque no le merece, como luego veréis» (599). Posteriormente, cuando el primo confiesa que escucha el relato de don Quijote con el mayor gusto del mundo, éste le contesta que lo cuenta con «no menor gusto» (601). Las «infinitas cosas y maravillas que me mostró Montesinos» (606) unidas a la alegría de ver nuevamente a Dulcinea han impresionado de tal manera a don Quijote que, como hace notar el primo, éste no se enfada con ninguno de los atrevimientos de Sancho: «Espantóse el primo, así del atrevimiento de Sancho Panza como de la paciencia de su amo, y juzgó que del contento que tenía de haber visto a su señora Dulcinea del Toboso, aunque encantada, le nacía aquella condición blanda que entonces mostraba» (610).

El encuentro con los personajes encantados, lejos de reflejar la degradación del mundo caballeresco, confirma a don Quijote el terrible poder de los encantadores y con ello refuerza su convicción en el encantamiento de Dulcinea, contra el parecer realista de Sancho: si Belerma puede hallarse en ese estado, con igual o mayor razón Dulcinea puede aparecer vestida de aldeana. Por último, el argumento de que la visita de don Quijote es, simbólicamente, un frustrado rescate de la orden de la caballería andante es contradicho por los buenos augurios de Montesinos: «Dijome asimesmo (Montesinos) que, andando el tiempo, se me daría aviso cómo habían de ser desencantados él, y Belerma, y Durandarte, con todos los que alli estaban» (607). Así, desde esta perspectiva, la visita a la cueva no indica una devaluación de los ideales caballerescos sino, por el contrario, anuncia su redención: el episodio explica la metamorfosis de Dulcinea a la vez que anuncia al caballero su futuro desencantamiento que, a fin de cuentas, es su mayor objetivo.

Ambos puntos de vista, como se ve, presentan angumentos convincentes aunque contradictorios. Mi tesis no pretende tomar partido por una perspectiva con exclusión de la otra sino senalar que esta contradicción es, justamente, lo significativo del episodio. La cueva de Montesinos es, valga el oxímoron, una pesadilla maravillosa, y expone la ambivalencia misma del héroe a lo largo de su 
tercera y última salida. Refleja, como ya dijimos, la coexistencia de dos paradigmas contradictorios que pugnan en su interior: el de Amadís y el suyo propio como personaje del Q1.

Dice Freud -y bastante antes que él Montaigne, contemporáneo de Cervantes ${ }^{3}$ - que el sueño refleja los conflictos o deseos del soñador mismo. El sueño de la cueva de Montesinos condensa en imágenes singulares -que detallaremos más adelante- las contradicciones que vive el héroe en esta segunda parte de la novela. La discusión académica sobre si don Quijote soñó esta escena o la inventó nos parece que no tiene mayor relevancia aquí, desde el momento en que éste la cuenta como si realmente la hubiera vivido en carne propia. Si éste hubiese mentido sobre sus visiones en la cueva no tendría sentido su posterior preocupación sobre la veracidad o no de ésta, preocupación expresada en sus preguntas al mono de Maese Pedro o a la cabeza parlante.

Es interesante apuntar las semejanzas entre el episodio de la cueva de Montesinos y el episodio - anterior- del caballero del lago (Capítulo L del Q1) para ver cual puede haber sido la «materia prima» del sueño del héroe. Tanto en el episodio de la cueva como en el del lago hay que descender por una superficie difícil y peligrosa para llegar a un «locus amenus», en medio del cual se levanta un "fuerte castillo o vistoso alcázar» (en el episodio del Q1) o un «palacio o alcázar» (en el episodio del Q2). Del mismo modo, tanto en el salón del castillo como en el del alcázar desfilan, ante la vista del caballero visitante, dos hileras de doncellas y una figura femenina principal que se destaca del resto. Pero los antecedentes del sueño de la cueva podemos rastrearlos aún más atrás, en la memoria de ese gran lector que fue Alonso Quijano. La idea del caballero que desciende al mundo subterráneo tiene antecedentes en la Eneida, en la historia cristiana (los tres días que Cristo permanece en los infiernos) y en las baladas carolingias, a cuya tradición pertenecen los personajes de Durandarte, Belerma y Montesinos.

Lo que interesa destacar aquí, sin embargo, no son las posibles fuentes del sueño como la metamorfosis que éste sufre en la mente del protagonista, y que son un reflejo de sus actuales preocupaciones. Metamorfosis que consiste en una condensación de rasgos de las novelas de caballería con otros de un mundo prosaico, y que, desde la perspectiva de don Quijote, no constituye ni una parodia ni una celebración de su mundo caballeresco, sino, como ya anotamos, una contradictoria inclusión de registros diversos en el escenario de su subconsciente.

3 Citado en Gethin Hughes, p. 106. 
Los personajes que circulan por la imaginación de don Quijote en la cueva de Montesinos condensan eficazmente elementos de la realidad cotidiana con otros que provienen del mundo de la épica: Durandarte, en su paradójica condición de «muerto-vivo», refleja a la vez la inmortalidad de la caballería andante y la propia condición mortal de don Quijote; es, en el sentido más cabal, su espejo, como se deduce de las palabras de Montesinos, evocadoras de las del propio hidalgo: «Este es mi amigo Durandarte, flor y espejo de los caballeros enamorados y valientes de su tiempo" (602). La descripción de Belerma manifiesta también la ambivalencia de registros, pues su rostro muestra, junto con los signos de la decadencia física, unos dientes blanquísimos, propios de las heroínas de las novelas de caballería. La comparación que Montesinos hace entre Belerma y Dulcinea (que no debemos olvidar es una comparación gestada por el propio subconsciente de don Quijote) revela su ambivalencia hacia ésta: Dulcinea es y no es Belerma; es y no es una figura degradada. Es interesante constatar, por otro lado, cómo Dulcinea aparece en ropas de aldeana pero no muestra su rostro en ningún momento; de este modo, a la vez que presenta una figura vulgar que desconsuela a su amante, preserva intacta su naturaleza ideal. La ambigüedad la encontramos también en la compañera de Dulcinea que le pide dinero a don Quijote de manera muy cortés y sentida -en el mejor estilo de las novelas de caballería-, para alejarse enseguida con una grotesca cabriola «que se levantó dos varas de medir en el aire» (608). Finalmente, como bien ha visto Alban Forcione, la ambigüedad se presenta en el plano del lenguaje pues concurren por lo menos dos códigos lingǘrsticos diferentes: uno épico y otro mundano, que hace eco al discurso «científico» del primo (a quien don Quijote ha escuchado anteriormente). Los detalles más grotescamente realistas se yuxtaponen con otros caballerescos: el corazón de «dos libras» de Durandarte expresa metafóricamente la valentía incomparable del héroe; pero a la vez la descripción que hace Montesinos de este corazón apela a un lenguaje de carnicería, más propio de Sancho que de un caballero andante, pues dice que ha tenido que echarle sal «porque no oliese mal, y fuese, si no fresco, a lo menos, amojamado, a la presencia de la señora Belerma" (602). La manera solemne y caballeresca del hablar de Montesinos contrasta también con el crudo contenido de su discurso, como cuando explica la postrada condición física de Belerma: «Y no toma ocasión su amarillez y sus ojeras de estar con el mal mensil, ordinario en las mujeres, porque ha muchos meses, y aún años, que no le tiene ni asoma por sus puertas» (606).

Así, tanto los discursos como la apariencia física de los personajes legendarios que participan en el sueño de la cueva de Monte- 
sinos muestran una imbricación de registros que si bien puede interpretarse como una parodia del autor, un guiño irónico que le hace al lector, no lo es desde el punto de vista del héroe, pues refleja la ambivalencia de su condición: la coexistencia en su imaginación de un intacto paradigma caballeresco y otro en vías de descomposición.

\section{Carlos SchWalb}

\section{OBRAS CITADAS}

Avalle-Arce, Junn Bautista, Don Quijote como forma de vida. Valencia, Editorial Castalia, 1976, pp. 173-213.

BAkHtn, Mnkun, "Discourse in the Novel». The Dialogic Imagination. Austin, University of Texas Press, 1988.

- Epic and Novel». The Dialogic Imagination. Austin, University of Texas Press, 1988.

Cervantes, Miguel De, Don Quijote de la Mancha. Buenos Aires, Ed. Joaquín Gil, 1944.

DunN, Peter, «La cueva de Montesinos por fuera y por dentro: estructura épica, fisonomiax. MLN, 88, pp. 190-202.

Forcione, Alban K., Cervantes, Aristotle, and the Persiles. New Jersey, Princeton University Press, 1970.

Grard, Rane, Mensonge Romantique et Vérité Romanesque. París, Grasset, 1961.

Hughes, Gethin, «The Cave of Montesinos: Don Quixote's interpretation and Dulcinea's disenchantment», Bulletin Hispanic Studies, 1977, pp. 106-113.

Parr, James, An Anatomy of Subversive Discourse. Delaware, Juan de la Cuesta ed., 1988.

Porcas Ponseti, Helen, «La cueva de Montesinos», Revista Hispánica Modema, XXXIV, pp. 376-399.

REed, WArTER, An Exemplary History of the Novel: The Quixotic versus the Picaresgue. Chicago, University of Chicago Press, 1981.

Rney, E. C., Don Quixote. London, Allen \& Unwin Publishers, 1986, pp. 140-143. 